\title{
Article \\ Performance Evaluation of Bio-Based Fractions Derived from Bacillus spp. for Potential In Situ Soil Stabilisation
}

\author{
Veshara Ramdas ${ }^{1,2, *, \dagger}$, Rajesh Lalloo ${ }^{2}$, Prisha Mandree ${ }^{2}$, Martin Mgangira ${ }^{2}$, Samson Mukaratirwa ${ }^{1}$ (D) \\ and Santosh Ramchuran 1,2,*,t
}

Citation: Ramdas, V.; Lalloo, R.; Mandree, P.; Mgangira, M.; Mukaratirwa, S.; Ramchuran, S. Performance Evaluation of Bio-Based Fractions Derived from Bacillus spp. for Potential In Situ Soil Stabilisation. Appl. Sci. 2022, 12, 1774. https:// doi.org/10.3390/app12041774

Academic Editor: Daniel Dias

Received: 5 January 2022

Accepted: 27 January 2022

Published: 9 February 2022

Publisher's Note: MDPI stays neutral with regard to jurisdictional claims in published maps and institutional affiliations.

Copyright: (C) 2022 by the authors. Licensee MDPI, Basel, Switzerland. This article is an open access article distributed under the terms and conditions of the Creative Commons Attribution (CC BY) license (https:// creativecommons.org/licenses/by/ $4.0 /)$.
1 School of Life Sciences, University of KwaZulu Natal, Durban 4041, South Africa; Mukaratirwa@ukzn.ac.za 2 Council for Scientific and Industrial Research (CSIR), Meiring Naude Road, Brummeria, Pretoria 0184, South Africa; RLalloo@csir.co.za (R.L.); PMandree@csir.co.za (P.M.); MMgangira@csir.co.za (M.M.)

* Correspondence: VMalapermal@csir.co.za (V.R.); SRamchuran@csir.co.za (S.R.); Tel.: +27-128413780 (V.R.); +27-128412664 (S.R.)

† Current address: The CSIR Future Production, Chemicals, Meiring Naude Drive, Brummeria, P.O. Box 395 , Pretoria 0001, South Africa.

\begin{abstract}
Current and future research focuses on the use of renewable technologies and materials to stabilise weak soils, of varying degrees, for road construction applications. Soil stabilisation is a method of strengthening a natural soil to meet this purpose. Our interest is in the use of bio-based components, derived from microbial growth processes, that contribute to the needed desirable strength characteristics for in situ soil stabilisation. This investigation focuses on novel Bacillus-based stabilisers obtained from the vegetative and spore growth stage. In this study, eighteen bio-based components were derived from a Bacillus licheniformis fermentation and extracted into various aqueous and non-aqueous fractions for strength property assessment. The strength properties of the treated soils (i.e., dolerite and weathered granite soil) were assessed via previously developed lab-scale equipment to rapidly pre-select the best performing fractions, (i.e., compression stress, erosion, abrasion, and water absorption tests). The effect of one superior performing prototype (a) was validated at large-scale, using standard erosion and abrasion tests (i.e., whole broth at $1.8 \%$ stabiliser concentrations), and showed resistance to abrasion $(3.37 \pm 0.03 \%)$ ( $p$ value $\leq 0.0001)$ and resistance to erosion $(33.20 \pm 0.15 \%)$ ( $p$ value $\leq 0.001)$. The elemental composition and microstructure of the bio-stabilised soil was determined using energy dispersive X-ray spectroscopy and scanning electron microscopy, respectively. This evaluation formed part of the selection of the best performing Bacillus derived fractions and achieved a proof of concept for the next phase of product prototype development. This study demonstrated a novel bio-mediated approach to the overall criteria for evaluation and selection of candidate product prototype/s, for stabilisation of two varying soils, and for potential application in road construction works.
\end{abstract}

Keywords: Bacillus species; bio-stabilisers; bio-polymers; microbial components; soil stabilisation; unpaved roads

\section{Introduction}

In any country the efficiency of ground transportation is highly dependent on the quality of their network of roads. In South Africa (SA) the national road network contains kilometers of unpaved (i.e., gravel) roads, as well as unclaimed roads or rural roads [1]. South Africa has more than 500,000 km of unpaved roads; however, these roads generally do not provide all-weather pass-ability, they are of poor riding quality, impassable in wet weather, and produce excessive dust in the dry weather. Yet, these roads are critical in providing access to rural and poorer areas, where the majority of the population reside. These roads are an important factor in supporting a rural-based economy of the country. 
Even though it is important in developing countries to uplift the socioeconomic conditions of communities, the prioritisation and improvement of these roads throughout the world are typically overlooked. This is seen with the issue of rural roads in particular, due to increasing environmental legislation, high-cost for upgrading and maintenance, and limited resources [2]. The practice of gravel replacement to maintain these roads is unsustainable. The solution is either to treat the material in situ with chemical additives or to upgrade to a surfaced road. The quality of typical soils for unpaved roads can be improved with traditional chemical additives such as, cement, lime, and bitumen. However, even with cement's numerous applications and low cost, it has been determined that the over-dependence and overuse has led to several global environmental concerns such as, high $\mathrm{CO}_{2}$ emissions, increase in $\mathrm{pH}(12-14)$, urban water runoff, heat islands, and prevention of vegetation growth. Furthermore, the use of cement itself does not always solve the issue of environmental compatibility, as soil-cement may not be compatible with weak dispersive clay for slope stabilisation [3].

Worldwide awareness enforces the use of greener technologies, specifically targeted at de-carbonising the global economy. With significant statistics supporting a bioeconomy there has been a strong drive from agencies such as, the South African National Roads Agency SOC Ltd. (SANRAL) to investigate alternative 'green' construction materials for road improvement and maintenance. Previous field investigation studies have shown the potential use of electrochemical-based non-traditional stabilisers (defined as chemical-based formulations or modified traditional stabilisers) to improve unpaved road performance [4]. However, in that study, it was difficult to conclude whether the enzyme based additives or the sulfonated oil showed significant improvement, due to variability in terms of the density of gravel, in situ strength based on dynamic cone penetration (DCP) results and California bearing ratio (CBR) testing, and the lack of knowledge on associated testing procedures for non-traditional additives (i.e., considering time, moisture regime, and traffic load intensity as factors). Non-traditional stabilisers are known to have mixed results and are material dependent. Good wearing course on unpaved or earthen roads should have the ability to resist the abrasive action of traffic and erosion by water. In this case, it is important to evaluate the requirements of non-traditional additives and properties of the wearing course materials for unpaved road applications in relation to their micro- and macro-structural performance.

Soil compatibility is, thus, a factor that needs consideration, as the effectiveness of the stabiliser/additive will vary with the soil type. The traditional choice and type of stabilisation depends on whether the soil has a high or low plasticity index (PI). This results in different processes and mechanism of stabilisation. Numerous proprietary chemical products such as Terrazyme and Permazyme are commonly investigated bio-enzyme based products. They have been found to give mixed results and confirm the findings of previous studies that enzyme-based products are soil material dependent. The claim by most of the suppliers of these products that it improves almost any soil type to a suitable quality for road construction, as well as the mixed results of the claims, has created a barrier to acceptability. It is important to assess the efficiency and efficacy of these products in a large-scale project, which may lead to modification of these existing products that will allow them to be acceptable to the industry. The proposal is the use of microbial biotechnology techniques, to drive research towards investigating alternative bio-inspired formulated materials, such as, microbial biomass, microbial cements, bio-polymers, and bioplastics [5].

With more research focusing on microbial methods, bio-based processes, and products, it is important to consider bio-stabilisers as possible alternatives to conventional chemical methods for construction applications. A well-known example is the use of highly active urease producing bacteria in a cementation process to bind loose soil particles together (i.e., microbially induced calcium carbonate precipitation (MICCP) [6,7].

This process provides sufficient evidence in mechanistic action of Bacillus spp. on the improved mechanical properties of treated soils [8]. Even though several studies have investigated microbial biocement, there is still limited knowledge and standardisation 
for the implementation of new biological products and processes (testing of in situ/inplace soil and pavement materials, in terms of strength and performance). Recently, there has been revived scientific interest in the use of extracellular polymeric substances (EPS) (i.e., bio-polymers) produced by Bacillus spp., with industry benefit [9]. Extracellular polysaccharides (exopolysaccharides) and proteins are the major components formed in these EPS systems [10]. One of the functional roles of the EPS matrix is their capacity to aggregate soil particles, since the slimy texture of EPS and ionic charges act as a 'glue' attaching clay minerals, ions, and solid particles together [11]. Similarly, studies have identified different types of bio-polymers (i.e., xanthan gum, guar gum, modified starches, glucan, casein, and sodium caseinate) that can improve the engineering properties of typical soils (sand, silt, and clay) [12,13]. Studies show that fermentation processes using the Bacillus spp. can produce similar bio-flocculent material, which are nontoxic and environmentally friendly compounds, comparative to conventional synthetic flocculants. Bio-flocculants have been produced, using B. licheniformis [10] and Halomonas spp., also known for their thermostability $\left(4-95^{\circ} \mathrm{C}\right)$ [14]; both show great potential as candidates for selection and evaluation in future studies $[14,15]$.

The aim of the paper is to evaluate and demonstrate the use of Bacillus licheniformis as potential bio-based solution for soil stabilisation. In this study, the fractions (polar and non-polar compounds) are hypothesised as the most suitable for the potential application on construction materials (i.e., fine grained soil and wearing course). The main objectives include, (a) evaluation of 18 macro-components (fractions) produced by B. licheniformis via small-scale strength testing, (b) the evaluation of appropriate microbial derived macrocomponents (fractions) using statistical assessment and novel matrices for selection of the best performers, (c) large-scale industry validation of the selected prototype/s.

\section{Materials and Methods}

\subsection{Cultivation of Bacillus sp. during Fermentation}

The isolate B. licheniformis (NCCB 100133) [16] was used for this study and a two-stage fermentation was carried out in a $10 \mathrm{~L}$ Biostat Braun $C$ reactor (Sartorius BBI Systems, Melsungen, Germany) under similar control parameters previously carried out by [17]. The inoculum was transferred into the bioreactor at an $\mathrm{OD}_{660 \mathrm{~nm}}$ of 4.33 . Similarly, once the fermentation culture reached the onset of stationary phase at 12:00-20:00 hour's fermentation after inoculation, residual glucose was low (i.e., the depletion of sugar correlated to the end of the exponential phase) and the desired cell concentration at this stage of growth had been reached $\left(>1.00 \times 10^{10}\right.$ cells $\left.\cdot \mathrm{mL}^{-1}\right)$. $5 \mathrm{~L}$ of whole broth (batch 1$)$ was recovered and stored in sterile containers at $4{ }^{\circ} \mathrm{C}$ for $24 \mathrm{~h}$ (refer to fermentation harvest times shown in Figure S1, Supplementary Material). The sporulation phase commenced $\sim 30 \mathrm{~h}$ into cultivation (i.e., formed small terminal ended endospores at the sporulation phase). The remaining fermentation broth was monitored until a sporulation efficiency of $>90 \%$ (fully formed spores, cell concentration of $1 \times 10^{10} \mathrm{CFU} \cdot \mathrm{mL}^{-1}$ ) was achieved after $40-48 \mathrm{~h}$; the harvested whole broth was stored at $4{ }^{\circ} \mathrm{C}$ for 7 days (batch 2) for subsequent preparation into test fractions. On the selected medium, the colonies appeared to be circular, transparent slimy, viscous, and creamy in colour.

\subsection{Pre-Treatment of Whole Fermentation Broth Fractions}

Fermentation whole broth (i.e., batch 1 -cell culture in stationary phase) was processed as follows, whole fermentation broth $(1.5 \mathrm{~L})$ was sampled from the fermenter; $500 \mathrm{~mL}$ of this sample was placed into a pre-labelled container and set aside for subsequent strength testing. Thereafter aqueous and non-aqueous extraction was performed using the remaining $1.0 \mathrm{~L}$ of the whole broth. Deionised water was used to extract the aqueous components containing polar compounds and hexane ( $>/=97 \%$ ) (Sigma-Aldrich (Pty.) Ltd., Darmstadt, Germany) was used to extract the non-aqueous components containing nonpolar compounds (Figure 1(a1,a2), respectively). An equivalent quantity of the deionised water and hexane (1:1) was added to the whole broth component, vigorously mixed for $1 \mathrm{~h}$ 
using a magnetic stirrer plate until layers were visible. The layers were separated according to densities using a sterile pipette (i.e., hexane the top layer) into pre-weighed tubes. The hexane was removed on a rotary evaporator (MERCK, Heidolph Laborota 4000 efficient, Schönwalde-Glien, Germany). Parameters include: pressure pump at $65 \mathrm{kPa}$ for $2-3 \mathrm{~h}$; condenser maintained at $4-6{ }^{\circ} \mathrm{C}$; evaporating flask rotation at $240 \mathrm{rpm}$ and maintained at $40^{\circ} \mathrm{C}$ with a water bath (MERCK, Buchi 461, Flavil, Switzerland). The fractions were left under a flow hood for $24 \mathrm{~h}$ (Airvolution Labs, FCC Fume hood, Gauteng, South Africa) [18]. The process was repeated using batch 2 (cell culture at $>90 \%$ sporulation efficiency). The whole broth and subsequent fractions (i.e., Figure $1(\mathrm{~d}, \mathrm{~d} 1, \mathrm{~d} 2)$ ) were capped and stored at $4{ }^{\circ} \mathrm{C}$ for use in the subsequent strength test experiments.

(a)

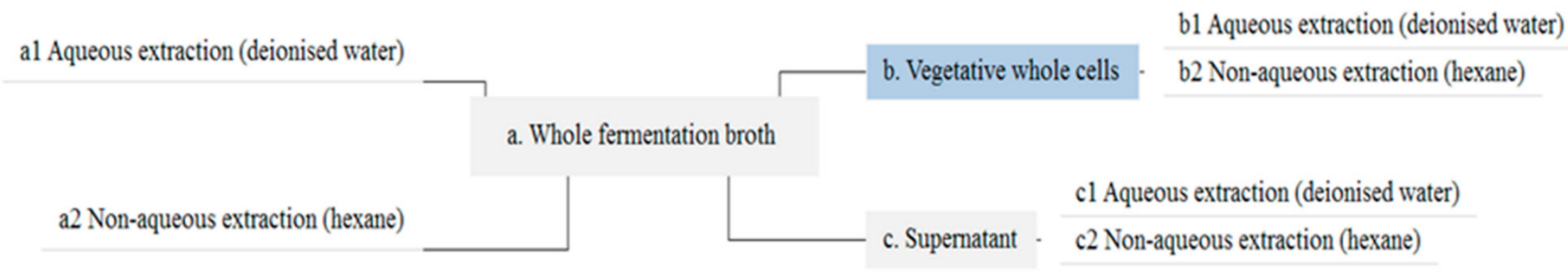

(b)

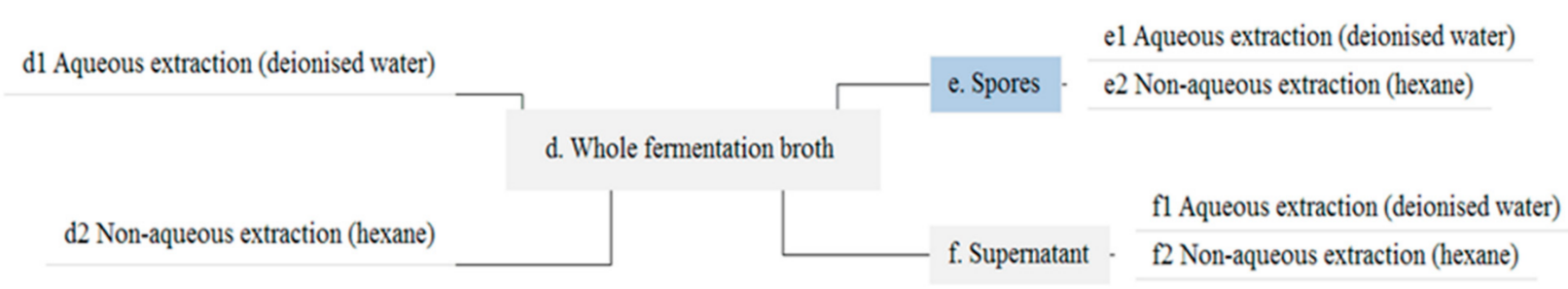

Figure 1. Process map for the production of candidate testing components obtained from the B. licheniformis fermentation, from (a) stationary phase (batch 1); (b) sporulation phase (batch 2), as well as the outline of the extraction into aqueous \& non-aqueous fractions.

\subsection{Pre-Treatment of the Pellet and Supernatant Fractions}

The fermentation pellet and supernatant (i.e., batch 1 -cell culture in stationary phase) were processed as follows, $3.0 \mathrm{~L}$ fermentation whole broth was centrifuged at $7700 \mathrm{rpm}$ for 10 min (Beckman Coulter, Avanti J-25l centrifuge with Rotor ID JA-10, Brea, CA, United States of America). This was placed into two sterile containers, labelled supernatant and the pellet, respectively, and then set aside: $200 \mathrm{~mL}$ of pellet and $500 \mathrm{~mL}$ of supernatant into pre-labelled containers for subsequent strength testing. The volumes were recorded after centrifugation and to each quantity (mass) of the pellet and supernatant, respectively, equivalent quantities of deionised water and hexane (1:1) were added. Thereafter, aqueous and non-aqueous extraction, and removal of hexane was performed as per the section above; the same process was followed with the supernatant. The process was repeated using batch 2: supernatant and pellet (cell culture at $>90 \%$ sporulation). The pellet, supernatant and whole broth and subsequent fractions were capped and stored at $4{ }^{\circ} \mathrm{C}$ for use in the subsequent test experiments. Treatment of batch 1 and 2 totaled to eighteen test fractions as per Figure 1.

\subsection{Preparation of Miniaturised Test Blocks}

The soils used in this study include, dolerite G8 by classification (soil type i) and weathered granite (soil type ii). It is classified as good quality soil for potential use in road construction and the soil was collected at depth from borrow pits in South Africa (i.e., to 
avoid the presence of organic matter) (Table S1, Supplementary Material). The dry densities versus moisture content graphs, particle size distribution curve were previously determined [17]. For this study, the concentration ( $2.5 \%$ by mass) was used according to typical application rates of non-traditional liquid stabilisers (dosage range 1.4-3\%) [19]. A material balance was developed to normalise each individual fraction, back to the original $10 \mathrm{~L}$ start volume of the ferment. The calculation, the relative volume to the $10 \mathrm{~L}$ fermentation, and the volume of the fraction per $1000 \mathrm{~g}$ soil material (Table S2, Supplementary Material). The fractions and each soil type listed were mixed using $25 \mathrm{~g}$ fraction (a) per $1000 \mathrm{~g}$ soil. The moisture content was pre-determined $( \pm 8 \%$, South African National Standard test SANS 3001-GR30:2015) and confirmed using a moisture analyser (Moisture analyser, HS153, Mettler Toledo, OH, USA), before mixing of the bio-additive/fraction in the soil and allowing the soil to be mellowed to achieve uniform mixture for compaction. The soil/bio-additive mixture was left to mellow for $12 \mathrm{~h}$ at room temperature and then fully compressed manually using a tablet press (Korsch, Berlin, Germany), to produce miniature soil blocks - compacted stabilised blocks with a dimension of $9 \mathrm{~mm}$ height $\times 13 \mathrm{~mm}$ diameter. The positive control, soil treated with a Permazyme product (Specialised Protection Products, Gauteng, South Africa), was prepared according to the manufacturer's instructions; the studies' negative control was untreated soil. The soil blocks were cured in a $25{ }^{\circ} \mathrm{C}$ incubator at a relative humidity $\sim 60 \%$, and after 7 days each treated and untreated soil block was checked for uniformity using a digital caliper (Insize, Loganville, GA, USA). After the 7-day curing period, the test blocks were removed from the incubator and placed in a tray for drying at $40^{\circ} \mathrm{C}$ in an oven (Memmert Incubator, Lasec, South Africa) for $2 \mathrm{~h}$ and then placed in a desiccator for $1 \mathrm{~h}$ to reach ambient temperature. The blocks were then weighed $(\mathrm{g})$ before commencing with the small-scale strength tests.

\subsection{Small-Scale Strength Tests}

The structural strength of the treated and untreated blocks was assessed using smallscale test compression, abrasion, erosion, and water absorption test equipment previously developed for high throughput screening to pre-select from multiple bio-based fractions (Table S3, Supplementary Material) [17]. The strength test criteria were expressed relative to the standard (ordinary Portland cement (OPC) was used as a known standard for comparison).

\subsection{Large-Scale Tests}

This phase of the study used weathered granite (i.e., medium plasticity index) as a preliminary measurement of effects, to show the performance of one bio-additive/prototype at two concentrations ( $1.8 \%$ and $1.4 \%$ by mass). The water ratio normalisation in the analysis was determined for suitable compaction using the Optimum moisture content/maximum dry density (OMC/MDD)) (Table 1) (South African National Standard test SANS 3001GR30:2015 Determination of the maximum dry density and optimum moisture content). Cylindrical block samples were produced in triplicate $(100 \mathrm{~mm}$ diameter and $115 \mathrm{~mm}$ height (Figure S2, Supplementary Material). 
Table 1. Maximum dry density/Optimum moisture content (MDD/OMC) determination for largescale testing.

\begin{tabular}{|c|c|c|c|c|c|}
\hline \multicolumn{6}{|c|}{ Permazyme Product, 14 mL } \\
\hline Sample mass (g) & 6000 & 6000 & 6000 & 6000 & 6000 \\
\hline Mass of stabiliser (g) & 84 & 84 & 84 & 84 & 84 \\
\hline Mass water added (g) & 96 & 156 & 216 & 276 & 336 \\
\hline \multicolumn{6}{|c|}{ Permazyme Product, $18 \mathrm{~mL}$} \\
\hline Sample mass (g) & 6000 & 6000 & 6000 & 6000 & 6000 \\
\hline Mass of stabiliser (g) & 108 & 108 & 108 & 108 & 108 \\
\hline Mass water added (g) & 72 & 132 & 192 & 252 & 312 \\
\hline \multicolumn{6}{|c|}{ Fraction (a) Prototype, $14 \mathrm{~mL}$} \\
\hline Sample mass (g) & 6000 & 6000 & 6000 & 6000 & 6000 \\
\hline Mass of stabiliser (g) & 84 & 84 & 84 & 84 & 84 \\
\hline Mass water added (g) & 156 & 216 & 276 & 336 & 396 \\
\hline \multicolumn{6}{|c|}{ Fraction (a) Prototype, $18 \mathrm{~mL}$} \\
\hline Sample mass (g) & 6000 & 6000 & 6000 & 6000 & 6000 \\
\hline Mass of stabiliser $(\mathrm{g})$ & 108 & 108 & 108 & 108 & 108 \\
\hline Mass water added (g) & 192 & 252 & 312 & 372 & 432 \\
\hline
\end{tabular}

\subsubsection{Performance-Based Test Methods}

Tests were undertaken on both treated and untreated materials to assess the performance of selected biostabiliser prototype. Standard erosion and abrasion tests were the most appropriate methods of evaluating the performance of the soil and were used as an initial grading of the stabilised soil properties. These two properties allow for selection from the test prototypes and as a preliminary basis to conduct further large-scale tests and field trials [20].

Brush Test

Three replicate specimens were prepared by compaction in a mould and then dry cured to constant mass at $50{ }^{\circ} \mathrm{C}$. After curing, the treated and untreated specimens were weighed, mounted in a brushing apparatus as shown in Figure S3 (Supplementary Material) and then subjected to 250 revolutions with a brush loading of $2.0 \mathrm{~kg}$. The brushed specimens were then weighed, and the mass loss was recorded as a percentage of the original mass. Treated specimens were then subjected to a further 250 revolutions before final weighing and determination of percentage mass loss. The average loss for the three specimens after 250 and 500 revolutions was reported. If the loss from any one specimen differed from the other two by more than five per cent, the test was repeated [21].

\section{Erosion Test}

Specimens were prepared in the same way as for the abrasion resistance test. After curing, the treated and untreated specimens were weighed, positioned in the test apparatus and then subjected to five minutes of water flow at a constant water head of $1.0 \mathrm{~m}$, as illustrated in Figure S4 (Supplementary Material). Excess water was allowed to drain for a further five minutes, after which the specimens were removed from the apparatus and dried at $105^{\circ} \mathrm{C}$ for $24 \mathrm{~h}$. The specimens were then weighed, and the percentage mass loss was recorded. The average loss for each set of three specimens is what was reported. Similarly as in the case of abrasion test, if the loss from any one specimen differed from the other two by more than five per cent, the test was repeated [21].

\subsubsection{Particle Size Distribution}

The respective particle size distributions of the samples are shown in Figure 2. The results are presented in terms of percentage finer by weight to particle size of weathered granite soil. 


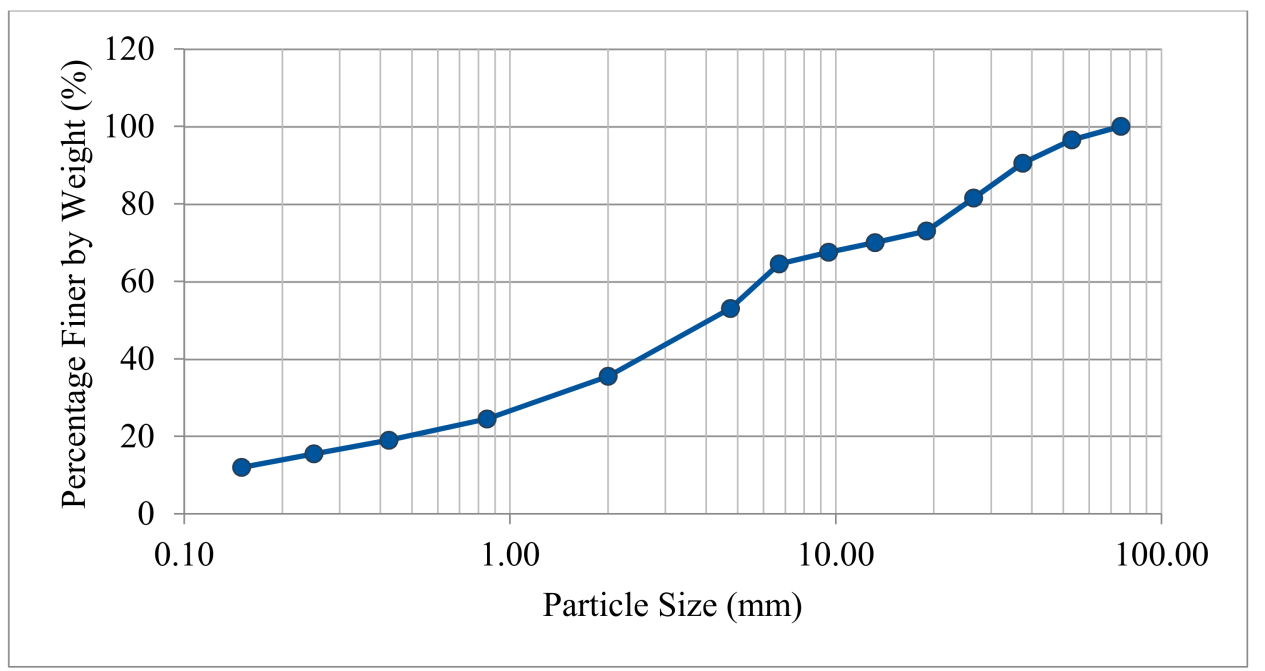

Figure 2. Particle size distribution curve (soil weathered granite).

\subsection{Scanning Electron Microscope-Energy Dispersive X-ray (SEM-EDX)}

The untreated and treated soil blocks (bio-stabilised soil) using the best performing fraction (fraction (a) whole fermentation broth) was analysed using a Phenom Pharos desktop scanning electron microscope (SEM) which has an energy dispersive X-ray (EDX) probe for semi-quantitative elemental analysis. The soil blocks were sectioned diagonally and vertically using a micro-blade for the microscope preparation. The samples were placed on carbon adhesive tape, sputter-coated using a Quorum $550 \times$ gold coater and then analysed at an accelerated voltage of $10 \mathrm{kv}$. The SEM images were obtained at a magnification ranging from $300 \times$ to $5000 \times$. The EDX scans were obtained at $500 \times$ and $1000 \times$.

\subsection{Data Analysis}

Univariate analysis of variance was carried out and the statistical comparisons were done with the Bonferroni test (multiple comparison test of the means and to determine which means are significantly different) using a statistical package program (GraphPad Prism ${ }^{\circledR} 5.03$ software for Windows). $p$ value $<0.05$ was regarded as statistically different between means and $p$ value $<0.001$ as statistically highly significant using the $t$-test. The scoring of each fraction and subsequent clusters were based on a standard deviation of $\pm 0.5 \mathrm{SD}$ ( $1 \mathrm{SD}$ total) of the mean of the data set Figure S5 (Supplementary Material).

The strength and durability testing screens consisted of the following, resistance to compression, abrasion, erosion, and water absorption. Each fraction was rated on a scale from 1 to 4 , where 1 represented lowest and 4 the highest score. The cumulative score ( $\mathrm{Si}$ ) was calculated by averaging the four tests, bearing in mind that each test had an equal importance (i.e., $25 \%$ ) to the selection. The maximum score was $100 \%$, where a fraction would need to score $4 / 4$ for each test (Equation (1)). The final selection was made based on the desirability of each fraction on all parameters tested. All scores obtained for each individual strength test were added to give an overall performance effect.

$$
\text { Cumulative score }(\mathrm{Si})=0.25 \times[(\mathrm{Si}, 1+\mathrm{Si}, 2+\mathrm{Si}, 3+\mathrm{Si}, 4) /(\mathrm{Si}, \max )] \times 100
$$

where,

$\mathrm{Si}, 1=$ Compression test score

$\mathrm{Si}, 2=$ Abrasion test score

$\mathrm{Si}, 3=$ Erosion test score

$\mathrm{Si}, 4=$ Water absorption test score

Si,max $=4$ (max score, 16 across all tests) 
The cumulative score results were separated into two growth stages (growth stage 1: vegetative phase; and growth stage 2: sporulation phase) for each soil type. The selection phase focused on the fermentation phase (vegetative and spores) and the soil type. Using the novel statistical strategy designed for this study, the criterion provides a selective basis of the best performing component (fraction) from each parameter that was set in the highthroughput screening tests (compression stress, abrasion, erosion, and water absorption tests). Once the selection of components (fractions) was completed, the best performer, including the commercial standard, was tested at large-scale. This includes compaction studies, erosion, and abrasion tests.

Technology design and development should not only meet technical requirements but should also provide other benefits over the traditional methods and existing technologies. The question is whether the use of the new technology is going to be cost effective and give financial, social or environmental benefit over the existing technology. Critical aspects to consider include cost, performance, and time. A cost equation is shown to further justify that cost, with time and performance is a primary measure in the criteria for final selection of the best performing fractions obtained from the various fermentation phases (i.e., batch 1 and batch 2) (Equation (2)).

Relative production cost : $\mathrm{Ct}=\left(\mathrm{Cc}_{1}+\mathrm{Cc}_{2}+\ldots+\mathrm{Cc}_{\mathrm{n}}\right)+\left(\mathrm{Cu}_{1}+\mathrm{Cu}_{2}+\ldots+\mathrm{Cu}_{\mathrm{n}}\right)+\left(\mathrm{Cl}_{1}+\mathrm{Cl}_{2}+\ldots+\mathrm{Cl}_{\mathrm{n}}\right)$

where,

$\mathrm{Ct}=$ Total production cost

$\mathrm{C} c=$ Cost of raw materials and consumables

$\mathrm{Cu}=$ Cost of utilities

$\mathrm{Cl}=$ Cost of labour

$\mathrm{n}=$ Cost components

3. Results

\subsection{Primary Assessment and Testing}

\subsubsection{Small-Scale Test Analysis}

The fractions were compared to the positive and negative controls and against each other. The average of the overall measurements that showed a mean value $<0.05$ ( $p$ value) indicated that the result was significant and supports the improvement in the strength characteristics. The methodology applied is a fast, reliable, and cost-effective screening tool for early assessment of structural properties allowing for prioritisation and selection of microbes and microbial components. This study shows that one or more components (fractions) of the fermentation material improved resistance to: compression, abrasion, erosion, and water absorption properties of the selected soils, designated as soil type $i$ and soil type ii.

\section{Evaluation of Compression Resistance}

The assay was based on the ability of a potential bio-stabiliser to resist compression, which would reduce deformation of the material or rutting when exposed to an applied stress. This would indicate maximum achievable strength characteristics. As illustrated in Figure 3 the fractions that showed improved compression resistance in comparison to the negative and positive control exhibited compression resistant properties. Fractions c2 $(10.06 \pm 0.53 \%, p$ value $<0.0001)$, using soil type $i$, showed a high resistance to compression stress of $>10 \mathrm{MPa}$ strength compared to the positive control $(8.52 \pm 0.83 \%, p$ value 0.0003$)$. Moreover, with soil type ii, fraction a2 $(16.15 \pm 0.43 \%, p$ value 0.0003$)$ compared to the positive control $(9.56 \pm 0.93 \%)$, and statistical significance $(p$ value $<0.0001)$. 
(a)

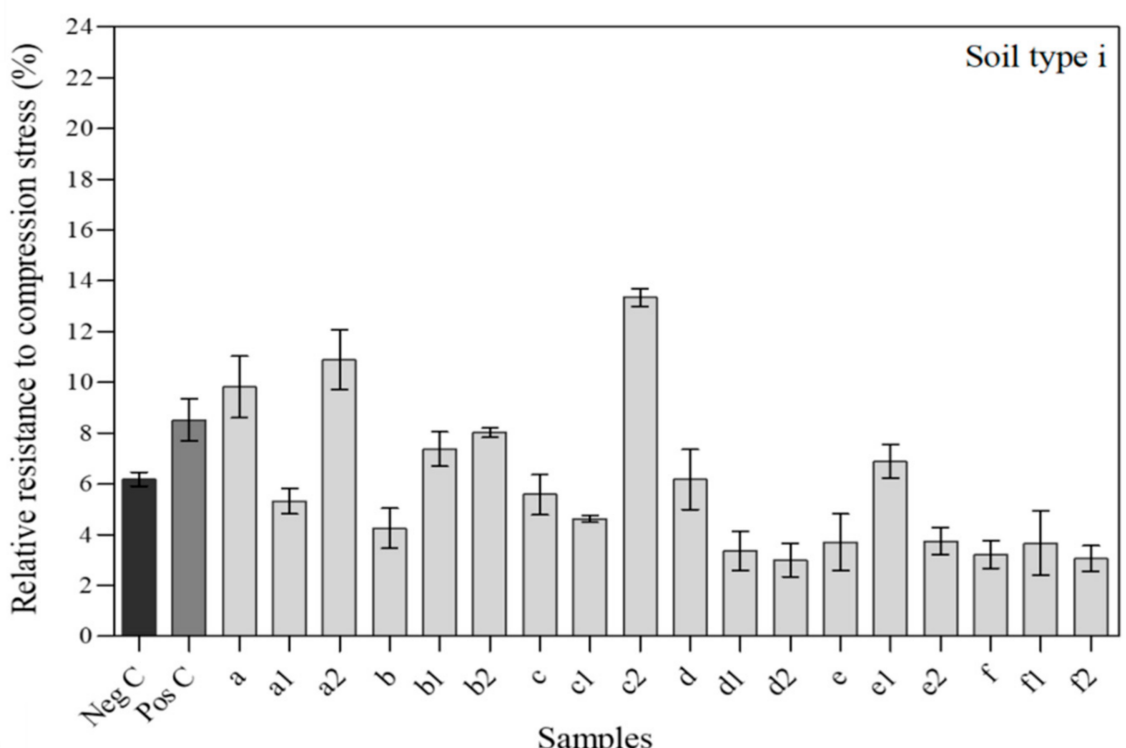

(b)

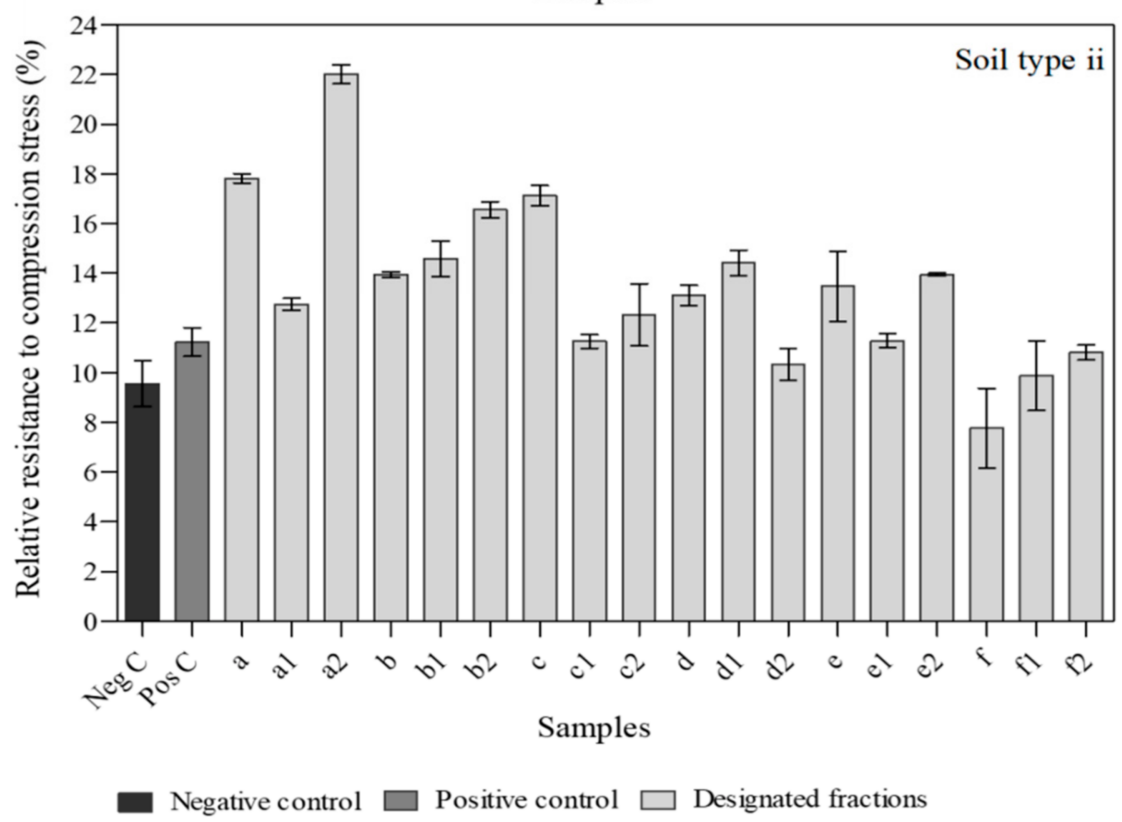

Figure 3. Compression breakage point showing (a) soil type $\mathrm{i}$ and (b) soil type ii, treated with fractions from the vegetative phase \& sporulation phase. Results expressed as mean $\pm \mathrm{SD} ; \mathrm{N}=6$; $p$ value (two-tailed) $p<0.05$ vs. control.

\section{Evaluation of Water Absorption Properties}

The assay was based on the ability of a potential bio-stabiliser to inhibit absorption of water, which would thereby limit loss of material and maintain form when exposed to external water penetration. The fractions that showed lower water absorption coefficients (Aw) indicated reduced absorptive properties in comparison to the negative and positive control water resistant properties. Fraction f1 (soil type i) $\left(1.097 \pm 0.12 \mathrm{~kg} \cdot \mathrm{m}^{-2} \cdot \mathrm{s}^{-1 / 2}\right)$ shows mean difference compared to the positive control $\left(0.401 \pm 0.01 \mathrm{~kg} \cdot \mathrm{m}^{-2} \cdot \mathrm{s}^{-1 / 2}\right)$, with statistical significance ( $p$ value 0.0004) Figure S6 (Supplementary Material). Whereas, fraction $b$ (soil type ii) indicated the best water absorption properties, $0.817 \pm 0.06 \mathrm{~kg} \cdot \mathrm{m}^{-2} \cdot \mathrm{s}^{-1 / 2}$, mean difference compared to the positive control $\left(0.282 \pm 0.01 \mathrm{~kg} \cdot \mathrm{m}^{-2} \cdot \mathrm{s}^{-1 / 2}\right)$, and shows a statistical significance ( $p$ value $<0.0001$ ). The fractions show statistically high absorptive property in comparison to the positive control (i.e., therefore the hydrophilic versus hydrophobic nature of fraction/s and its cohesion effect may vary with the two soils). Neither 
wearing course nor the subgrade (to a lesser extent) should deform under applied loads in either wet or dry conditions. A lack of stability results in general deformation, rutting, or potholes [22]. Therefore, the following best performing prototypes that exhibited resistance to water are presented. As shown in Figure 4, the untreated dolerite and weathered granite showed $<40 \%$ resistance to water and completely disintegrated after 6 min due to weak adhesion among the soil particles, and many fine particles were dispersed. Comparatively, the treated soils with $2.5 \%$ stabiliser (samples a, b2 and e2 tested on dolerite soil; and samples a, and $\mathrm{d}$ tested on weathered granite soil) improved significantly ( $p$ value $<0.05)$ (refer to the statistical analysis Tables S4 and S5 (Supplementary Material)). Furthermore, prototype (d) resistance effect appeared to be better than the positive control product ( $p$ value $<0.001$ ).
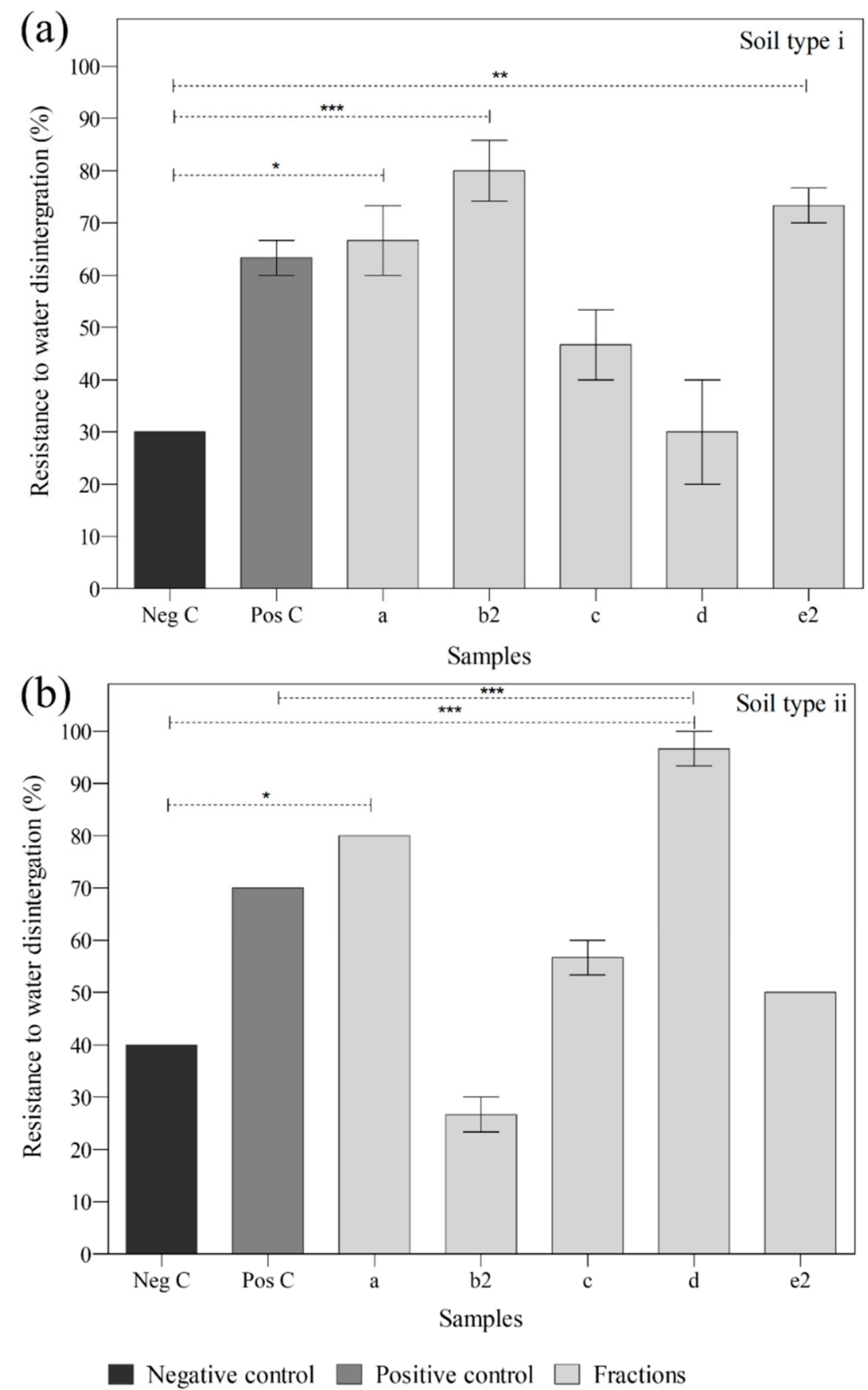

Figure 4. Lab-scale water resistance test showing untreated and treated soil with candidate soil bio-stabilisers (a) tested on soil type i, (b) tested on soil type ii. Key: ${ }^{*} p$ value $<0.05,{ }^{* *} p$ value $<0.01$, *** $p$ value $<0.001$ 


\section{Evaluation of Abrasion Resistance}

The assay was based on the ability of potential bio-stabilisers to inhibit abrasion, which is the capacity to limit the loss of material when exposed to harsh weather or vehicles. Additionally, it is well established that long-term exposure to traffic generated dust from unpaved roads can be attributed to serious health problems from the effects of exposure to high concentration of airborne particulates. The fractions that resulted in minimal loss of material in comparison to the negative and positive control were viewed as having abrasion resistant properties. As can be seen in Figure S7 (Supplementary Material), several fractions, including (b2) (i.e., $98.57 \pm 0.005 \%$, $p$ value $<0.0001$ ) (i.e., statistical significance against the negative control, $p$ value $<0.0001)$, displayed the highest resistance to abrasive action on both soil types.

\section{Evaluation of Erosion Resistance}

The assay was based on the ability of a potential bio-stabiliser to inhibit erosion, which is the capacity to limit loss of material caused by running water. The fractions that showed minimal loss of material in comparison to the negative and positive control exhibited erosion resistance properties. As shown in Figure S8 (Supplementary Material), several fractions, including fraction (a), showed statistical significance $(98.90 \pm 0.06 \%$, $p$ value $<0.0001)$ in comparison to the positive control $(83.04 \pm 0.54 \%, p$ value $<0.0001)$ and thus resistance to erosion on soil type ii.

\subsection{Data Evaluation and Selection from Primary Assessment and Testing}

The performance of the various test fractions in each pre-defined structural criterion was measured in the high-throughput screening test protocol. The data identified the eighteen fractions from the growth phases that met the desirable strength characteristics. The whole fermentation broth, pellet, and supernatant (subsequent aqueous and nonaqueous fractions) were compared to the positive and negative controls and against each other. The average of the overall measurements showed a mean value $p$ value $<0.05$ compared to the negative and positive controls indicated that the result was significant and supports the improvement in the strength characteristics. All scores obtained for each individual strength test were added to give an overall effect. Using this strategy, results showed that fractions a, b2, d, e, e1, and e2 performed significantly higher than the average performers ( $p$ value $<0.05)$.

The final selection resulted in six candidate fractions that displayed the highest cumulative desirability co-efficient (80-90\%) (Tables 2 and 3). Whole broth (a) \& whole vegetative cells (non-aqueous) (b2) (obtained from the vegetative growth phase) showed maximum efficiency from the stationary phase. In addition, a second level of selection was introduced based on preliminary cost of manufacture (prototypes), which required the cost of the top performing fractions to be assessed. The results show that fraction (a) had the lowest cost of production. At this stage, it is not a direct comparison with the benchmark Permazyme product as the production process requires scaling and process optimisation for production. However, fraction (d) and (b2)'s cost of production was $2 \times$ and $10 \times$ greater, respectively. The cost equation is shown to further justify that cost, with time and performance is a primary measure in the criteria for final selection of the best performing fractions obtained from the various fermentation phases (i.e., batch 1 and batch 2) (Equation (2)). Thus, upon further analysis of this consortium for prototype testing, the whole broth (a) provided the best overall performance in contrast to (b2). Overall, the remaining best performing outlined in Tables 2 and 3 scored statistically higher than the rest and were selected as the main consortium and was further targeted at product prototype development for the envisioned structural applications. 
Table 2. Desirability co-efficient of each fraction showing suitability to each criteria and cumulative multi-mode performance rating (relative \% to maximum), on soil type i.

\begin{tabular}{|c|c|c|c|c|c|}
\hline $\begin{array}{l}\text { Components } \\
\text { (Fractions) }\end{array}$ & $\begin{array}{c}\text { Resistance to } \\
\text { Compression Load }\end{array}$ & $\begin{array}{l}\text { Resistance to } \\
\text { Erosion }\end{array}$ & $\begin{array}{l}\text { Resistance to } \\
\text { Abrasion }\end{array}$ & $\begin{array}{c}\text { Water } \\
\text { Absorption }\end{array}$ & $\begin{array}{c}\text { Cumulative } \\
\text { Score }\end{array}$ \\
\hline \multicolumn{6}{|c|}{ Desirability Co-Efficient (\%) } \\
\hline $\mathrm{b} 2$ & 75 & 100 & 100 & 100 & $94 \%$ \\
\hline $\mathrm{e} 2$ & 50 & 100 & 100 & 100 & $88 \%$ \\
\hline e1 & 100 & 33 & 100 & 100 & $83 \%$ \\
\hline a & 75 & 50 & 100 & 100 & $81 \%$ \\
\hline b1 & 50 & 50 & 100 & 100 & $75 \%$ \\
\hline c2 & 100 & 50 & 100 & 33 & $71 \%$ \\
\hline $\mathrm{e}$ & 50 & 33 & 100 & 100 & $71 \%$ \\
\hline $\mathrm{f}$ & 50 & 33 & 100 & 100 & $71 \%$ \\
\hline f2 & 50 & 33 & 100 & 100 & $71 \%$ \\
\hline $\mathrm{b}$ & 25 & 50 & 100 & 100 & $69 \%$ \\
\hline a2 & 75 & 50 & 33 & 100 & $65 \%$ \\
\hline $\mathrm{d} 1$ & 25 & 33 & 100 & 100 & $65 \%$ \\
\hline a1 & 25 & 50 & 67 & 100 & $60 \%$ \\
\hline c & 25 & 50 & 100 & 67 & $60 \%$ \\
\hline c1 & 25 & 50 & 100 & 67 & $60 \%$ \\
\hline f1 & 25 & 67 & 100 & 33 & $56 \%$ \\
\hline $\mathrm{d} 2$ & 25 & 33 & 67 & 100 & $56 \%$ \\
\hline $\mathrm{d}$ & 50 & 33 & 33 & 100 & $54 \%$ \\
\hline
\end{tabular}

Key: soil type i-dolerite a: fermentation broth in batch one, a1: aqueous fraction, a2: non-aqueous fraction, b: pellet (whole vegetative cells), b1: aqueous fraction, b2: non-aqueous fraction, c: supernatant, c1: aqueous fraction, c2: non-aqueous fraction; d: fermentation broth in batch two, d1: aqueous fraction, d2: non-aqueous fraction, e: pellet (spores $>90 \% \mathrm{SE}$ ), e1: aqueous fraction, e2: non-aqueous fraction, f: supernatant, f1: aqueous fraction, f2: non-aqueous fraction.

Table 3. Desirability co-efficient of each fraction showing suitability to each criteria and cumulative multi-mode performance rating (relative \% to maximum), on soil type ii.

\begin{tabular}{|c|c|c|c|c|c|}
\hline $\begin{array}{l}\text { Components } \\
\text { (Fractions) }\end{array}$ & $\begin{array}{c}\text { Resistance to } \\
\text { Compression Load }\end{array}$ & $\begin{array}{l}\text { Resistance to } \\
\text { Erosion }\end{array}$ & $\begin{array}{l}\text { Resistance to } \\
\text { Abrasion }\end{array}$ & $\begin{array}{c}\text { Water } \\
\text { Absorption }\end{array}$ & $\begin{array}{c}\text { Cumulative } \\
\text { Score }\end{array}$ \\
\hline \multicolumn{6}{|c|}{ Desirability Co-Efficient (\%) } \\
\hline $\mathrm{d}$ & 100 & 67 & 100 & 75 & $85 \%$ \\
\hline $\mathrm{e}$ & 100 & 33 & 100 & 100 & $83 \%$ \\
\hline $\mathrm{d} 1$ & 100 & 33 & 100 & 75 & $77 \%$ \\
\hline $\mathrm{d} 2$ & 33 & 100 & 100 & 75 & $77 \%$ \\
\hline $\mathrm{e} 2$ & 100 & 33 & 100 & 75 & $77 \%$ \\
\hline a & 75 & 75 & 75 & 75 & $75 \%$ \\
\hline c & 75 & 75 & 75 & 75 & $75 \%$ \\
\hline e1 & 67 & 33 & 100 & 75 & $69 \%$ \\
\hline b2 & 75 & 25 & 75 & 75 & $63 \%$ \\
\hline $\mathrm{c} 1$ & 25 & 75 & 75 & 75 & $63 \%$ \\
\hline b1 & 50 & 25 & 75 & 75 & $56 \%$ \\
\hline a1 & 25 & 25 & 75 & 75 & $50 \%$ \\
\hline a2 & 100 & 25 & 25 & 50 & $50 \%$ \\
\hline $\mathrm{b}$ & 50 & 25 & 75 & 50 & $50 \%$ \\
\hline c2 & 25 & 75 & 75 & 25 & $50 \%$ \\
\hline $\mathrm{f}$ & 33 & 33 & 100 & 25 & $48 \%$ \\
\hline $\mathrm{f} 1$ & 33 & 33 & 100 & 25 & $48 \%$ \\
\hline f2 & 33 & 33 & 33 & 50 & $38 \%$ \\
\hline
\end{tabular}

Key: soil type ii-weathered granite; a: fermentation broth in batch one, a1: aqueous fraction, a2: non-aqueous fraction, b: pellet (whole vegetative cells), b1: aqueous fraction, b2: non-aqueous fraction, c: supernatant, c1: aqueous fraction, c2: non-aqueous fraction; d: fermentation broth in batch two, d1: aqueous fraction, d2: nonaqueous fraction, e: pellet (spores $>90 \% \mathrm{SE}$ ), e1: aqueous fraction, e2: non-aqueous fraction, f: supernatant, f1: aqueous fraction, f2: non-aqueous fraction. 


\subsection{Secondary Evaluation and Testing at Large-Scale}

Based on the results obtained from the primary evaluation and testing, fraction (a) (namely, whole fermentation broth) was evaluated in a large-scale trial. This fraction is now termed prototype 1. Dry density versus moisture content graph is shown (Figure 5). As in Table 4 the preliminary assessment on one soil type in this screen, shows resistance to abrasion $(3.37 \pm 0.03 \%)(p$ value $\leq 0.0001)$ and resistance to erosion $(33.20 \pm 0.15 \%)$ ( $p$ value $\leq 0.001$ ) using $18 \mathrm{~mL}$ dosage of the bio-stabiliser at large-scale (Figures S3 and S4 (Supplementary Material)). From the statistical comparison, the results show the large-scale test results, as well as the mean values obtained for the positive and negative controls. The tests utilise loss of material as a primary measure in both methods. At $14 \mathrm{~mL}$ dosage the resistance to abrasion and erosion declines. Therefore, by using an increased concentration, the stabiliser effect improves (see Figure 6).

(a)

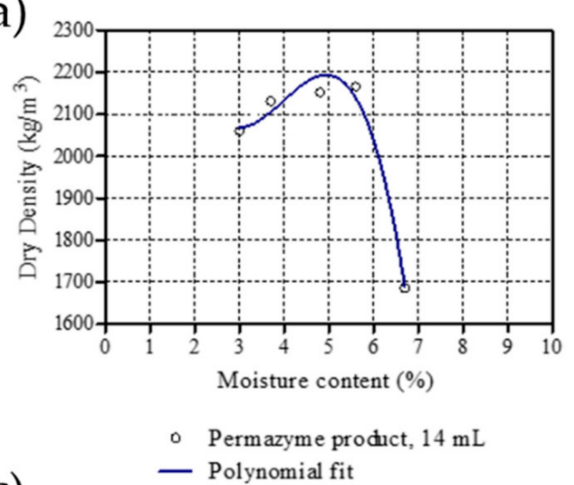

(c)

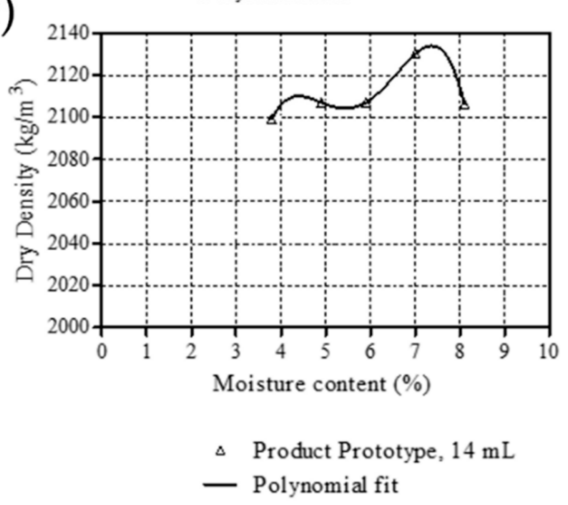

(b)

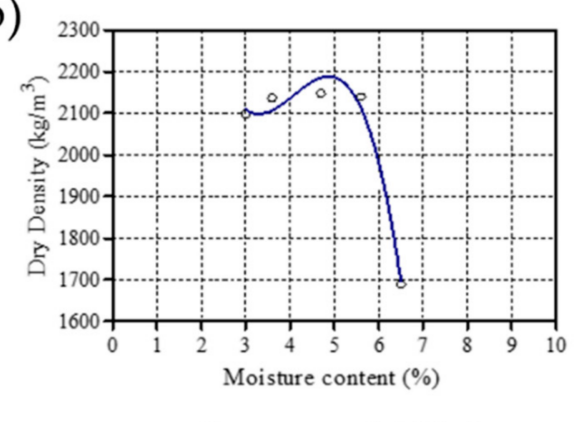

(d)

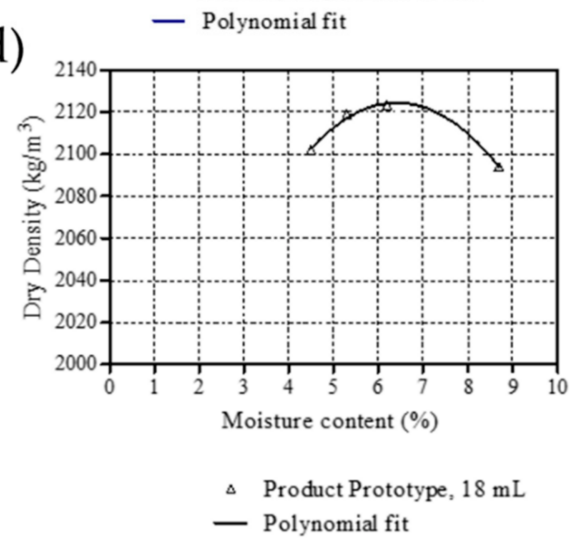

Figure 5. Dry density versus moisture content graph (a) Permazyme product, (14 mL), (b) Permazyme product $(18 \mathrm{~mL}),(\mathbf{c})$ Prototype, $(14 \mathrm{~mL}),(\mathbf{d})$ Prototype, $(18 \mathrm{~mL})$. 
Table 4. Large-scale industry testing showing $1.4 \%$ and $1.8 \%$ concentration of stabiliser (i.e., Prototype 1: whole fermentation broth from batch one) tested on soil type ii.

\begin{tabular}{|c|c|c|c|c|c|c|}
\hline \multirow[b]{2}{*}{ Strength Test } & \multicolumn{3}{|c|}{$1.4 \%$ Concentration } & \multicolumn{3}{|c|}{$1.8 \%$ Concentration } \\
\hline & Mean (\% Loss) & $\mathrm{CV} \%$ & $p$ Value & Mean (\% Loss) & $\mathrm{CV} \%$ & $p$ Value \\
\hline \multicolumn{7}{|c|}{ Abrasion test } \\
\hline $\begin{array}{c}\text { Neg C-after } \\
250 \text { revs }\end{array}$ & 4.90 & 1.25 & $<0.0001$ & 4.90 & 1.25 & $<0.0001$ \\
\hline $\begin{array}{c}\text { Neg C - after } \\
500 \text { revs }\end{array}$ & 11.20 & 0.09 & $<0.0001$ & 11.20 & 0.09 & $<0.0001$ \\
\hline $\begin{array}{c}\text { Pos } C \text {-after } \\
250 \text { revs }\end{array}$ & 4.467 & 3.42 & 0.0004 & 4.00 & 0.00 & $<0.0001$ \\
\hline $\begin{array}{c}\text { Pos } C \text { - after } \\
500 \text { revs }\end{array}$ & 8.700 & 1.15 & $<0.0001$ & 7.800 & 1.25 & $<0.0001$ \\
\hline Prototype & & & & & & \\
\hline $\begin{array}{c}1 \text {-after } 250 \\
\text { revs }\end{array}$ & 4.333 & 10.66 & 0.004 & 3.367 & 1.71 & $<0.0001$ \\
\hline $\begin{array}{c}\text { Prototype } \\
1 \text {-after } 500 \\
\text { revs }\end{array}$ & 10.07 & 0.57 & $<0.0001$ & 9.067 & 0.064 & $<0.0001$ \\
\hline \multicolumn{7}{|c|}{ Erosion test } \\
\hline $\operatorname{Neg} C$ & 47.00 & 0.12 & $<0.0001$ & 46.90 & 0.02 & $<0.0001$ \\
\hline Pos C & 25.50 & 0.02 & $<0.0001$ & 22.60 & 2.34 & 0.0002 \\
\hline Prototype 1 & 36.20 & 0.48 & $<0.0001$ & 33.20 & 0.80 & $<0.0001$ \\
\hline
\end{tabular}

Key: Neg C-negative control; Pos C-positive control; revs-revolutions.

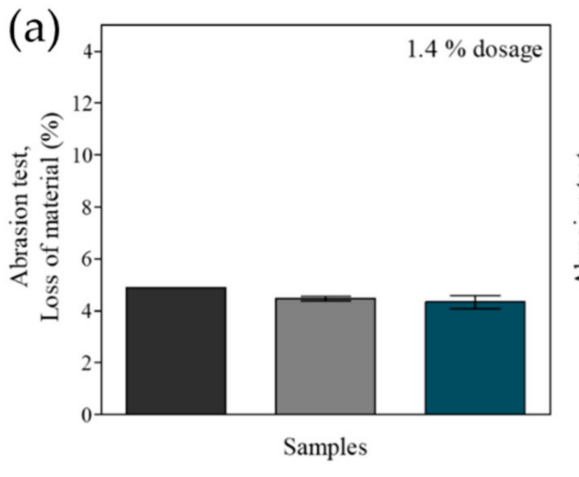

Negative control - after $\square$ Positive control - after 250 revs

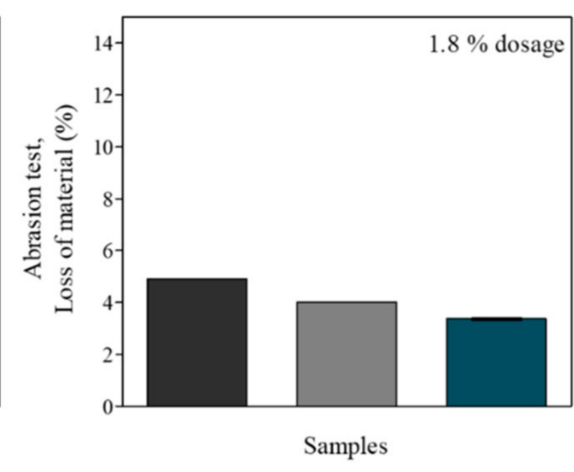

Prototype -

after 250 revs

(b)
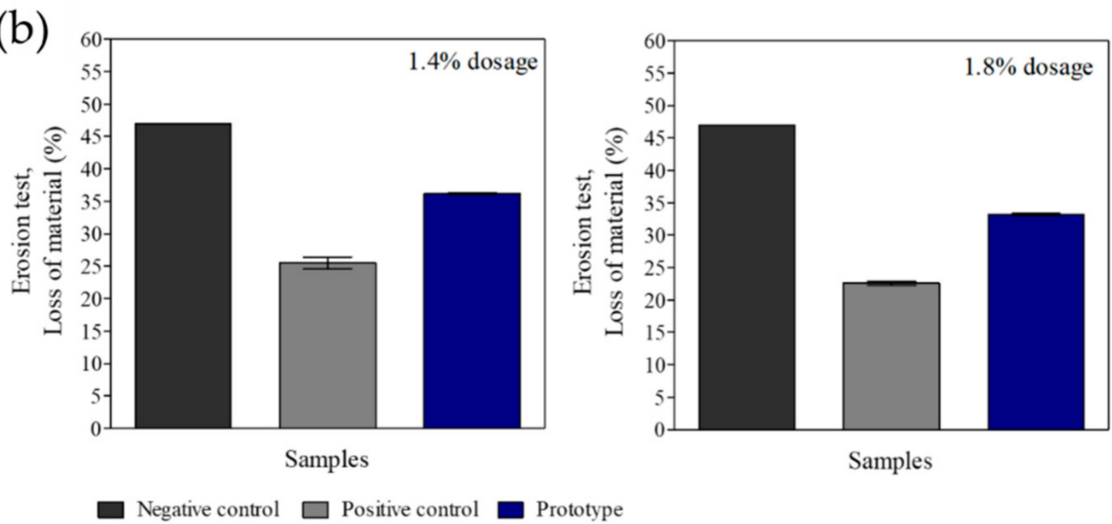

Figure 6. Large-scale testing of the best prototype showing (a) abrasion and; (b) erosion test results. Results expressed as mean $\pm \mathrm{SD} ; \mathrm{N}=3 ; p$ value (two-tailed), $p<0.05$ vs. control. 


\subsection{Microscopic Soil-Structure Analysis Using SEM-EDX}

The surface morphology and the elemental composition of treated soil particles were analysed using SEM-EDX. The images were used to observe the micro-scale interaction (i.e., visualisation of interactive effects) between the soil and the best performing fraction.

Figure 7a-d shows the results of the SEM testing on treated weathered granite (WG), and the selected fraction. The untreated WG block/sample exhibited an arranged book- and cluster-like micro-structure [23]. The surface morphology of the WG soil sample, treated with $2.3 \%$ of the fraction (Figure $7 \mathrm{a}-\mathrm{d}$ ), highlights a region of compacted soil versus the pores present on the block surface. Based on the results, it was found that the stabilisation process modifies the porous network of this soil type. In addition, as shown in Figure $7 \mathrm{~d}$, new white layers of reaction products were formed on the surface of WG soil particles, with more structured and rigid soil particle stacking morphology was observed, as shown in Figure 7c, which is indicative of the bio-coating stabilisation effect. This micro-structure also shows closer bonding of particles of the treated soil, thereby increasing its stability.

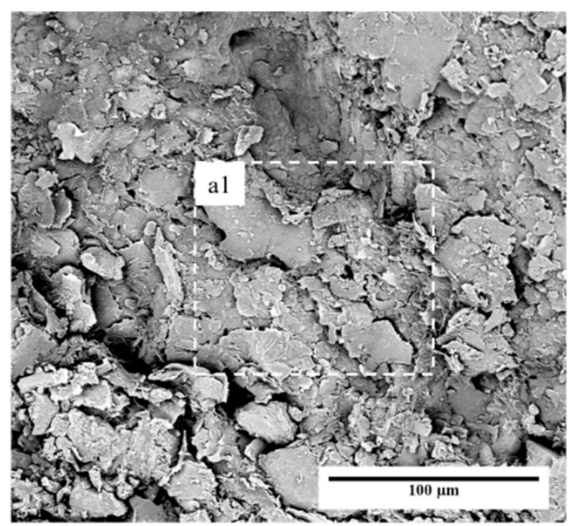

(a)

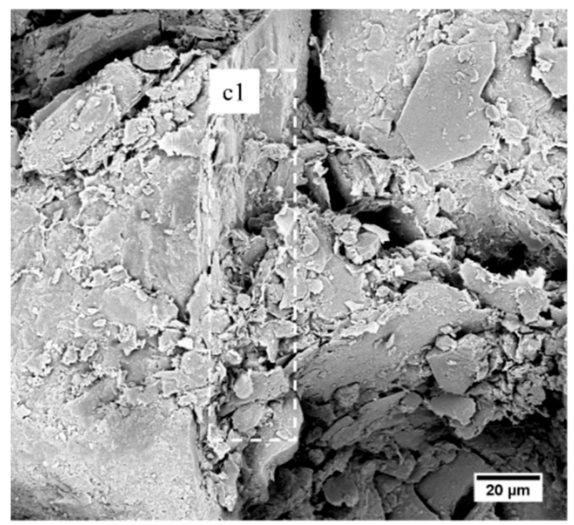

(c)

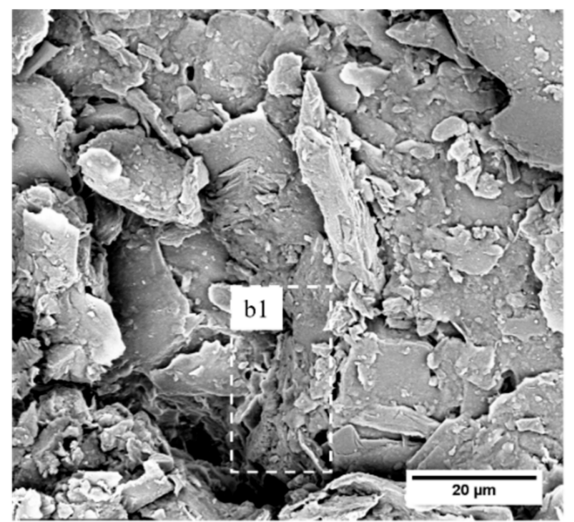

(b)

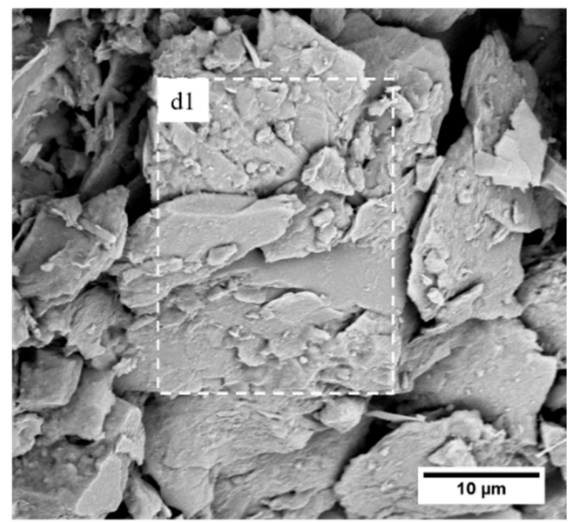

(d)

Figure 7. SEM micrographs showing (a-d) weathered granite soil treated with the best prototype (a) (2.3\% dosage). Key: (a1) — covered with a pellicle of fine material also traces of the much smaller particles on the surfaces of these grains; (b1)—showing white surface coat, or surface polymeric coating; (c1)—soil inter-particle stacking; (d1) —aggregates of soil material, area compacted particles with minimal pore spaces, the visible however pore space and edges (black) —induced by breakage on the blocks.

As an approach to further understand the mechanism of the soil stabiliser, EDX was used. This approach is important for two reasons, (1) assess any changes in the soil elemental composition and (2) further understand the bio-stabilisers mechanism of action. A combination of silicon ( $\mathrm{Si}$ ) and aluminium (Al) was picked up in several EDX micrographs (see Figure 8). This is typical for expansive soils. After treatment of the soil, silica and alumina sheets may combine in various ways, however these combinations may 
be indicative of weak van der Waals forces and may retain more water. The presence and extent of the pellicle of fine material covering the grains of the samples can be related to the mineralogical composition of this soil type which play a role in the performance of the soil after treatment (Figure $8 b$ ).

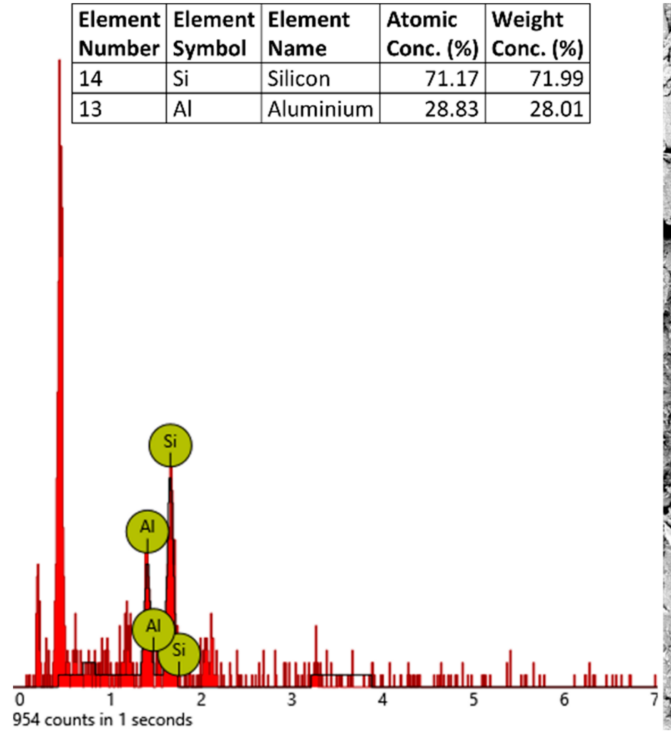

(a)

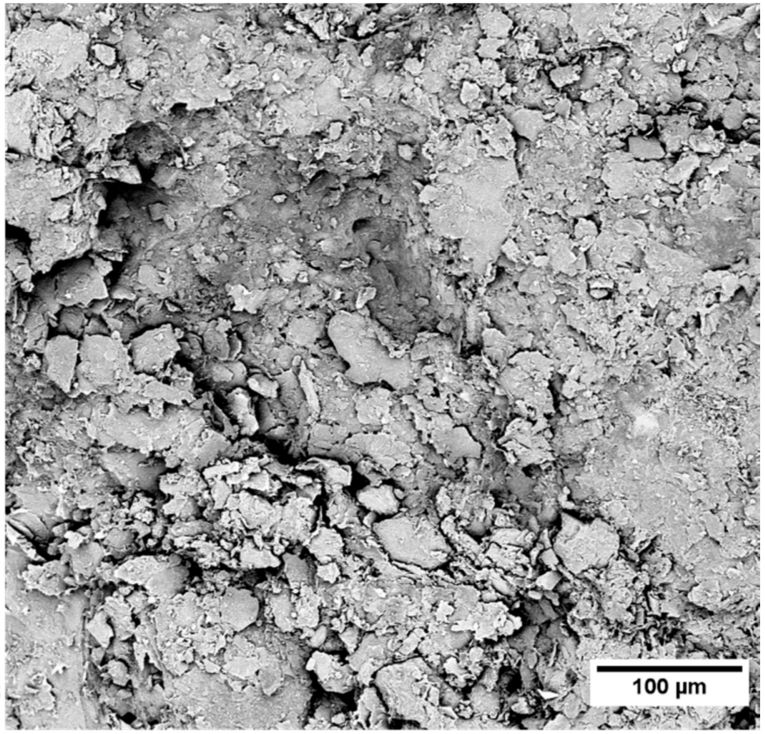

(b)

Figure 8. SEM-EDX micrographs showing (a,b) showing (a) EDX elemental composition, and (b) SEM image analysed showing fine material micro-aggregates between the grains.

\section{Discussion}

The research-obtained and evaluated microbial macro-components produced by Bacillus sp., representative of the following key components, active whole cells, spores, enzymes, bio-polymers, and sticking agents for potential soil stabilisation application. The selection of $B$. licheniformis for cultivation at $10 \mathrm{~L}$ scale was due to its previous use as an industry product and its production of extracellular substances of interest [24]. Due to its documented use as a stabiliser, it is a logical starting point to investigate the biostabilising properties of various fermentation derived macro-components. Two separate batches were harvested at specific time points from the fermentation, as the aging process was hypothesised to increase the production of extracellular components of benefit. An extraction technique was performed on each fermentation harvest (i.e., vegetative and sporulation) with the aim of potentially extracting "sticky agents" / bio-polymers from the various components (i.e., whole fermentation broth, supernatant, vegetative cells, and spores). The extracellular substances (mixture of unknown compounds) extracted from each component were defined by the method used to separate the macro-components (i.e., polar compounds-aqueous extraction, and non-polar compounds-non-polar extraction). The selected method is consistent with general extraction to whole cell bacteria and bio-transformation that requires a hydrophobic solvent and exhibits higher biocatalyst compatibility [18]. In the study's first phase, development of the upstream processing (USP) and downstream processing (DSP) technology provided a fit for purpose process. The result from this phase of the study showed the production of multiple test fractions that can be used as starting material for the small-scale strength testing. This process can be repeated using various other microbes and bio-based testing components. Therefore, at a later stage the scale up studies include optimizing the fermentation conditions for maximum EPS production (which will then require detailed isolation), analysis, identification, and characterisation of polymeric substances from B. licheniformis. In the area of EPS production by Costa et al. [11] high EPS production by B. licheniformis (strain HYTAPB18) showed 
a better aggregation effect with a larger bacterial population size and larger incubation periods for EPS production which results in a soil aggregation effect.

In the second phase, the impact of all the fractions of the fermentation material was tested for the desired effect for soil stabilisation. The rationale for this study was that one or more components (fractions) of the fermentation material show resistance to: abrasion, erosion, compression, and exhibit water absorptive properties. For the testing of the macrocomponents and fractions, a series of small-scale strength tests enabled assessment of the multiple samples in a high-throughput method, to select the best performing fractions. The statistical evaluation (i.e., quantification of multiple effects/structural criteria into test matrices) was used to measure the criteria of interest, regarding the structural stabilisation of the selected soil material and enabled the selection of the best performing fractions. In detail, the performance of disintegration resistance (water resistance properties) was better in stabilised soil. As with a previous investigation the stabilised soil remained cohesive and minimally deformed over the short time [25], which was attributed to the agglomeration of soil particles into larger units in the stabilised soil samples. Furthermore, the stabilised soil type i (dolerite) treated with the non-aqueous prototypes namely, (b2) and (e2) showed significant resistance to water erosion. The observed effect showed the hydrophobicity resulted in stronger bond formation and ultimately water resistance. The inverse was shown using soil type ii (weathered granite), whereby prototype (d) (i.e., whole broth from the sporulation phase) showed improved water stabilisation properties and will therefore be further investigated. The study for product prototype development focused on the selection of fractions by the investigation of specific structural criteria of interest to soil stabilisation. The final selection resulted in six fractions that displayed the best overall performance over the entire screen. The various fractions possess either aqueous or non-aqueous properties. Therefore, different functional groups may be present (i.e., OH-groups-ionic bonds versus $\mathrm{C}-\mathrm{H}$-groups - covalent bonds) and will engage in either hydrogen bonding or stronger intermolecular interactions mechanisms as with the candidate non-aqueous fractions [23]. It is important to note that all six did not perform the best in every criterion but had the top average performance in all four screens. The testing also informs process development for large-scale product prototype production.

A calculation of cost in this study shows that the highest performer would not necessarily be the most feasible. Factors to consider include time (i.e., 12-h fermentation opposed to 48 -h full fermentation process), downstream manufacturing processes (DSP), and cost calculation (i.e., cost of utilities, consumables, and labor). This approach has not previously been researched, hence the novelty aspects in this approach include screening, selection, and quantitative evaluation based on multiple criteria and may result in a commercially usable product.

The third phase comprised of assessing the dry density versus moisture content of the test prototype, and standard large-scale erosion and abrasion resistance study. The weathered granite soil sample is a typical material that can potentially be used for wearing course on unpaved roads and in lower sub layers of pavement in South Africa [26]. Thus, it was the selected soil for the next phase of the bio-treatment prototypes (using the selected fraction (a) - whole fermentation broth, at two dosages). Resistance to abrasion and erosion characteristics was evaluated after the samples were left to cure for $24 \mathrm{~h}$ using one fraction and varying concentrations, revealed a mixed effect on strength. The prototype showed superior results (i.e., brush test) versus the benchmark permazyme product at 250 revolutions, with aggressive brushing at 500 revolutions, the loss of material is higher. Whereas, with water erosion performance is lower. In assessing the effectiveness of nontraditional additives as stabilisers for sandy soils, Jones and Ventura [21] recommend that the material loss should be less than 10 percent after 500 brushing revolutions and 8 percent after being subjected to $5 \mathrm{~min}$ of water flow in an erosion test. Both criteria were used in analyzing the results. The resistance to both erosion and abrasion was improved for specimens of samples treated at $2.3 \%$ dosage previously indicated by Ramdas et al. [17]. In these tests, one prototype bio-stabiliser product was evaluated and as part of the objective 
of the performance assessment at large-scale verifies the stabilising effect of the small-scale analysis. However, additional testing is required to better understand the implications in terms of strength requirements. Zhan et al. [27] investigated the wind and rainfall-erosion resistance of the biological treated material for fugitive dust control and engineering application. Firstly, the influence of increased dosage and wind speed $4-12 \mathrm{~m} \cdot \mathrm{s}^{-1}$ showed $<30 \mathrm{~g} / \mathrm{m}^{2} \cdot \mathrm{h}^{-1}$ loss of material compared to the negative control at $2600 \mathrm{~g} / \mathrm{m}^{2} \cdot \mathrm{h}^{-1}$ at maximum wind speed; secondly, the mass loss of the treated material was $<100 \mathrm{~g} / \mathrm{m}^{2} \cdot \mathrm{h}^{-1}$ compared to $750 \mathrm{~g} / \mathrm{m}^{2} \cdot \mathrm{h}^{-1}$ of the untreated; therefore, the biological carbonates possessed rainfall resistance properties $[27,28]$. To introduce new bio-based products in the road industry (construction practice), strategic large-scale experiments (test sections) with real weather and site conditions are necessary. Since soil characteristics for road construction purposes are highly dependent on location (as a result of soil formation mechanisation, climatic condition) and are affected by construction techniques, field trial sections are essential. The trial sections will provide the best method to assess, demonstrate, and verify performance of the bio-stabiliser within the actual operational environment. Trial sections are planned for the next stage of the technology development process and are beyond the scope of this study.

The small-scale tests provided a rapid method to select the best performing biobased fractions of interest. The initial testing programme focused on demonstrating the effectiveness of the bio-additive in terms of bonding performance. Determination of the strength properties for design purposes, including compressive and advanced strength testing, such as triaxial shear strength and resilient modulus, will form part of the next phase of the testing programme using the prototypes. Two different soil types obtained from specific sites in South Africa were selected for in situ/in-place soil stabilisation. Focus was on the potential for improving weak subgrade soil, as well as wearing course for unpaved roads. Better understanding of the multiple components derived from microbes could result in potential application on unpaved, low volume roads and expansion of applications (i.e., pavements, bio-bricks, slope stability, reduction of base material) and ultimately result in cheaper manufacturing processes and environmentally friendly road construction methods.

It is important to consider the bio-compatibility of the stabiliser and the varying soil types (i.e., fine grained, coarse grained, highly plasticity or clay soil). High plastic soil commonly shows bonding mechanisms via hydrogen or ionic bonding-as shown by using gellan gum, an anionic polymer which is expected to attach to positively charged kaolinite particle edges and to enhance plate particle stacking. Whereas, coarse grains (low-medium plasticity) showed improvement by interparticle cohesion with stronger bonds and the resultant strengthening property can be attributed to the conglomeration of the soils [28]. Chang and Cho [28] show different soil stabilisation mechanisms, (a) bioadditive soil matrix may be enhanced by the direct sheer cohesion, and conglomeration effect by the bio-additive induced matrices, (b) higher strength due to reduced liquid limit induced by hydrophilic additive treatments, and (c) as with non-plastic soils, when fully dried the bio-additives displayed an increase in frictional angle contact between the soil particles, forming surface coating and enlarging the interparticle contact area. The high strength achieved with gellan gum-treated soil was shown to be due to the water absorption characteristics of hydrophilic polymers but, with varying soil types, the interaction may vary, e.g., between expansive soil as opposed to a coarse grained [29]. Furthermore, the SEM-EDX images show bio-based cementitious gel-material produced from the candidate prototype, and their "sticky agents" / bio-polymers derived from the various components provide evidence of improved soil applications. One of the noted research questions for future studies include associating key biomolecules present in the fractions, which can create durable bonding mechanisms between the soil particles, and their associated strength effect on each soil type. 


\section{Conclusions}

The results obtained from this study demonstrated an assessment process of the eighteen-potential bio-based stabilisers. In this study, four comprehensive tests (combined) evaluated the overall performance of potential bio-stabilisers for soil improvement by enhancing strength properties. The strength tests have proven to be important factors to determine the effectiveness of soil particle reinforcement. From this study, out of eighteen fractions, six proved to have superior strength and durability properties based on the key measurements (i.e., erosion resistance, abrasion resistance, water absorption, and compression stress resistance). Generation of the scoring matrices identified key components for further large-scale testing and characterisation of products that may serve as an alternative solution for soil stabilisation in comparison to the benchmark product. It is also advantageous that Bacillus spp. produce numerous extracellular substances with potential structural benefit. Strategic approach to testing of non-traditional additives prior to field verification is important before introducing new bio-based products to industry. Moreover, collaborative studies are required on biological based stabilisers for an accepted level for road sector applications (i.e., unpaved roads and pavements). Further studies are necessary in understanding the application of bio-stabiliser/s at large-scale, to select the most effective and economical method for improving material currently used in the road construction industry. It is acknowledged that only two types of soil samples have been used and that some soils may not react favorably using the same application rates. Reactivity may also vary within a material source, at a borrow pit. Further testing of the compatibility between different soil materials and the formulation product will therefore be carried out to develop a data set for defining fit-for-purpose application.

Supplementary Materials: The following supporting information can be downloaded at: https: / / www.mdpi.com/article/10.3390/app12041774/s1, Figure S1: Biomass harvesting steps of the fermentation to recover the vegetative cells, and spores ( $>90 \%$ sporulation efficiency), Figure S2: Test formats for large scale testing, Figure S3: The strategy used to score the fractions based on the performance criteria of the strength tests (i.e., representing one criteria, compression load), Figure S4: Lab scale water resistance test showing untreated and treated soil with candidate soil bio-stabilisers, Figure S5: Large scale testing, Figure S6: Summary of the results of the water absorption coefficient (Aw), Figure S7: Abrasion test results showing treated and untreated material (a) soil type i and (b) soil type ii, testing vegetative and spore state fractions. Results expressed as mean $\pm \mathrm{SEM} ; \mathrm{N}=3$; $p$ value (two-tailed) $p<0.05$ vs. control, Figure S8: Erosion test results showing treated and untreated soil; (a) soil type i and (b) soil type ii testing vegetative and spore state fractions. Results expressed as mean \pm SEM; $\mathrm{N}=3 ; p$ value (two-tailed) $p<0.05$ vs. control; Table S1: Characteristics of the natural soil type i and soil type ii; Table S2: Typical fermentation and material balance; Table S3: Small scale strength tests; Table S4: Effect of water on deformation, statistic against the biological fractions (soil type i); Table S5: Effect of water on deformation, statistic against the biological fractions (soil type ii).

Author Contributions: Conceptualization, V.R., R.L., P.M., M.M., S.M. and S.R.; Data curation, V.R.; Formal analysis, V.R.; Funding acquisition, V.R. and S.R.; Investigation, V.R.; Methodology, V.R., P.M., M.M. and S.R.; Project administration, V.R.; Resources, V.R. and S.R.; Software, V.R.; Supervision, R.L., S.M. and S.R.; Validation, V.R.; Visualization, V.R.; Writing—original draft, V.R.; Writing—review and editing, V.R., R.L., P.M., M.M., S.M. and S.R. All authors have read and agreed to the published version of the manuscript.

Funding: This research was funded by Department of Science and Innovation, South Africa (ZA) and the Council for Scientific and Industrial Research, South Africa (ZA).

Institutional Review Board Statement: Not applicable.

Informed Consent Statement: Not applicable.

Data Availability Statement: Data is contained within the article or Supplementary Material.

Acknowledgments: The authors would like to thank Prabashni Lekha (microscopist) for FEGSEM and EDX. 
Conflicts of Interest: The authors declare that they have no conflict of interest. This article does not contain any studies with human participants or animals performed by any of the authors.

\section{References}

1. Chakwizira, J. Exploring linkages between transport and disaster risk reduction in South Africa: A review of literature. Jàmbá J. Disaster Risk Stud. 2019, 11, 1-9. [CrossRef] [PubMed]

2. Jordaan, G.; Kilian, A.; Muthivelli, N.; Dlamini, D. Practical Application of Nano-technology in Roads in southern Africa. In Proceedings of the 8th Transportation Technology Transfer (T2) Conference, Lusaka, Zambia, 8-10 May 2017.

3. Buritatun, A.; Takaikaew, T.; Horpibulsuk, S.; Udomchai, A.; Hoy, M.; Vichitcholchai, N.; Arulrajah, A. Mechanical strength improvement of cement-stabilized soil using natural rubber latex for pavement base applications. J. Mater. Civ. Eng. 2020, 32, 04020372. [CrossRef]

4. Moloisane, R.; Visser, A.T. Evaluation of the strength behaviour of unpaved road material treated with electro-chemical-based non-traditional soil stabilisation additives. J. South Afr. Inst. Civ. Eng. J. Van Die Suid-Afrik. Inst. Van Siviele Ing. 2014, 56, 28-39.

5. Barberán, A.; Chávez, D.; Cajas, A.; Egas, M.; Criollo, M.; Pineda, J.; País-Chanfrau, J.; Trujillo, L. A new area of application and research in bio-processes: Biotechnologies in civil construction. Rev. Bionatura 2020, 5, 1072-1077. [CrossRef]

6. Castro-Alonso, M.J.; Montañez-Hernandez, L.E.; Sanchez-Muñoz, M.A.; Macias Franco, M.R.; Narayanasamy, R.; Balagurusamy, N. Microbially induced calcium carbonate precipitation (MICP) and its potential in bioconcrete: Microbiological and molecular concepts. Front. Mater. 2019, 6, 126. [CrossRef]

7. Liu, B.; Zhu, C.; Tang, C.-S.; Xie, Y.-H.; Yin, L.-Y.; Cheng, Q.; Shi, B. Bio-remediation of desiccation cracking in clayey soils through microbially induced calcite precipitation (MICP). Eng. Geol. 2020, 264, 105389. [CrossRef]

8. Feng, C.; Cui, B.; Ge, H.; Huang, Y.; Zhang, W.; Zhu, J. Reinforcement of recycled aggregate by Microbial-Induced mineralization and deposition of calcium carbonate-Influencing factors, mechanism and effect of reinforcement. Crystals 2021, 11, 887. [CrossRef]

9. Aguilar, M.R.; San Román, J. Smart Polymers and Their Applications, 2nd ed.; Woodhead Publishing: Swaston, UK, 2019; pp. 1-9.

10. Asgher, M.; Urooj, Y.; Qamar, S.A.; Khalid, N. Improved exopolysaccharide production from Bacillus licheniformis MS3: Optimization and structural/functional characterization. Int. J. Biol. Macromol. 2020, 151, 984-992. [CrossRef]

11. Costa, O.Y.; Raaijmakers, J.M.; Kuramae, E.E. Microbial extracellular polymeric substances: Ecological function and impact on soil aggregation. Front. Microbiol. 2018, 9, 1-14. [CrossRef]

12. Ayeldeen, M.; Negm, A.; El-Sawwaf, M.; Kitazume, M. Enhancing mechanical behaviors of collapsible soil using two bio-polymers. JRMGE 2017, 9, 329-339.

13. Fatehi, H.; Abtahi, S.M.; Hashemolhosseini, H.; Hejazi, S.M. A novel study on using protein based bio-polymers in soil strengthening. Constr. Build. Mater. 2018, 167, 813-821. [CrossRef]

14. Abd El-malek, F.; Farag, A.; Omar, S.; Khairy, H. Polyhydroxyalkanoates (PHA) from Halomonas pacifica ASL10 and Halomonas salifodiane ASL11 isolated from Mariout salt lakes. Int. J. Biol. Macromol. 2020, 161, 1318-1328. [CrossRef]

15. Tran, T.N.T.; Nguyen, T.D.P.; Dinh, H.T.; Bui, T.T.; Ho, L.H.; Nguyen-Phan, T.X.; Khoo, K.S.; Chew, K.W.; Show, P.L. Characterization of bacteria type strain Bacillus spp. isolated from extracellular polymeric substance harvested in seafood wastewater. J. Chem. Technol. Biotechnol. 2021. [CrossRef]

16. Lalloo, R.; Ramchuran, S.; Ramduth, D.; Gorgens, J.; Gardiner, N. Isolation and selection of Bacillus spp. as potential biological agents for enhancement of water quality in culture of ornamental fish. J. Appl. Microbiol. 2007, 103, 1471-1479. [CrossRef]

17. Ramdas, V.M.; Mandree, P.; Mgangira, M.; Mukaratirwa, S.; Lalloo, R.; Ramchuran, S. Establishing miniaturised structural testing techniques to enable high-throughput screening of microorganisms and microbial components for unpaved road stabilisation application. J. Adv. Res. 2020, 21, 151-159. [CrossRef]

18. Leis, D.; Lauß, B.; Macher-Ambrosch, R.; Pfennig, A.; Nidetzky, B.; Kratzer, R. Integration of whole-cell reaction and product isolation: Highly hydrophobic solvents promote in situ substrate supply and simplify extractive product isolation. J. Biotechnol. 2017, 257, 110-117. [CrossRef]

19. Mgangira, M. Evaluation of the Effects of Enzyme-Based Liquid Chemical Stabilisers on Subgrade Soils; Southern African Transport Conference (SATC): Pretoria, South Africa, 6-9 July 2009.

20. Mgangira, M. Properties controlling the resistance to abrasion and erosion of stabilized sandy soils using non-traditional additives In Proceedings of the 17th International Conference on Soil Mechanics and Geotechnical Engineering: The Academia and Practice of Geotechnical Engineering, Alexandria, Egypt, 5-9 October 2009; IOS Press: Amsterdam, The Netherlands, 2009.

21. Jones, D.; Ventura, D. A procedure for fit-for-purpose certification of non-traditional road additives. In Proceedings of the 24th Southern African Transport Conferenc (SATC), Pretoria, South Africa, 11-13 July 2005.

22. Rauch, A.; Harmon, J.; Katz, L.; Liljestrand, H. Measured effects of liquid soil stabilizers on engineering properties of clay. Transp. Res. Rec. 2002, 1787, 33-41. [CrossRef]

23. Ramdas, V.M.; Lalloo, R.; Lekha, P.; Mgangira, M.; Muniyasamy, S.; Mukaratirwa, S.; Ramchuran, S. Understanding the mechanism of interaction of candidate soil stabilizing prototypes by using microscopy and spectroscopy techniques. Microsc. Res. Tech. 2021, 84, 2652-2665. [CrossRef]

24. Spanò, A.; Gugliandolo, C.; Lentini, V.; Maugeri, T.L.; Anzelmo, G.; Poli, A.; Nicolaus, B. A novel EPS-producing strain of Bacillus licheniformis isolated from a shallow vent off Panarea Island (Italy). Curr. Microbiol. 2013, 67, 21-29. [CrossRef] 
25. Pu, S.; Hou, Y.; Ma, J.; Zou, Y.; Xu, L.; Shi, Q.; Qian, S.; Pei, X. Stabilization behavior and performance of loess using a novel biomass-based polymeric soil stabilizer. Environ. Eng. Geosci. 2019, 25, 103-114. [CrossRef]

26. Mshali, M.; Visser, A.T. Influence of mica on unconfined compressive strength of a cement-treated weathered granite gravel. J. South Afr. Inst. Civ. Eng. J. Van Die Suid-Afrik. Inst. Van Siviele Ing. 2012, 54, 71-77.

27. Zhan, Q.; Qian, C.; Yi, H. Microbial-induced mineralization and cementation of fugitive dust and engineering application. Constr. Build. Mater. 2016, 121, 437-444. [CrossRef]

28. Chang, I.; Cho, G.C. Shear strength behavior and parameters of microbial gellan gum-treated soils: From sand to clay. Acta Geotech. 2019, 14, 361-375. [CrossRef]

29. Xiong, Y.; Wang, Y.; Yu, Y.; Li, Q.; Wang, H.; Chen, R.; He, N. Production and characterization of a novel bioflocculant from Bacillus licheniformis. Appl. Environ. Microbiol. 2010, 76, 2778-2782. [CrossRef] 